\title{
ÚNG DỤNG KỸ THUẬT PHÂN LOẠI HƯỚNG ĐỐI TƯợNG TRONG PHÂN LOẠI LỚP PHỦ VÙNG CỦA SÔNG BA LẠT
}

\author{
TRÀN THI NGOAN \\ Đại học Tài Nguyên và Môi trường Hà Nội
}

\section{Tóm tắt:}

Bài báo trình bày kết quả ưng dụng kỹ thuật phân loại hương đối tượng để xác định lớp phủ vùng cưa sông Ba Lạt tù̀ ảnh Landsat 5TM. Quá trình này được thực hiện theo 3 bước: phân mảnh ảnh, lấy mẫu và phân loại đối tượng, kiểm tra và đánh giá độ chính xác kết quả phân loại. Các đối tuợng trên ảnh được phân thành 8 nhóm bao gồm lúa, rùng ngập mặn (RNM), vuờn tạp, mặt nước, đât nuôi trồng thủy sản (NTTS), đất xây dụng (ĐXD), đất làm muối và đất chưa sủ dụng (CSD). Kết quả phân loại cho độ chính xác cao với độ chính xác tổng thể $92.24 \%$ và hệ số Kapa đạt 0.88 .

\section{1. Đặt vấn đề}

Trước đây, việc phân loại ảnh sử dụng kỹ thuật giải đoán bằng mắt hoặc định hướng điểm ảnh (Pixel - base) trên cơ sở điều tra mẫu ngoài thực địa. Kỹ thuật này dễ thực hiện và cho kết quả nhanh chóng nhưng lại phụ thuộc vào kinh nghiệm của người giải đoán. Hiện nay, sự xuất hiện của kỹ thuật phân loại hướng đối tượng được xem là giải pháp khắc phục tính chủ quan của kỹ thuật giải đoán bằng mắt. Lê Thị Thu Hà (2016) đã sử dụng các chỉ số Brightness, Greeness, Wetness, SAVI, NDVI để phân loại các đối tượng trên ảnh [3]. Trịnh Thị Hoài Thu (2015) so sánh hàm liên thuộc để xác định các tập mẫu cho kết quả phân loại đạt độ chính xác cao [2]. Nguyễn Văn Thị, Trần Quang Bảo (2014) đã sử dụng kỹ thuật phân loại hướng đối tượng để xác định trạng thái rừng dựa vào khóa giải đoán từ kết quả điều tra thực địa [1]. Để phân biệt các loại lớp phủ thực vật khác nhau như rừng, cây ăn quả, lúa, hoa màu,... và phân biệt lớp phủ thực vật với các loại lớp phủ khác cần phải sử dụng một bộ quy tắc (rule set) bao gồm Brightness, NDBI, NDVI, NDWI, SAVI, kết hợp với lựa chọn ảnh Landsat được chụp vào thời điểm lúa đã thu hoạch đã giúp chiết tách được thông tin lớp phủ với độ chính xác cao.

Vùng cửa sông $\mathrm{Ba}$ Lạt là vùng đồng bằng ven biển tiêu biểu, chứa đựng những giá trị sinh thái và đa dạng sinh học vào bậc nhất tại Việt Nam, đồng thời có tầm quan trọng quốc tế. Lớp phủ nơi đây tương đối đa dạng bao gồm: dân cư, đất nông nghiệp, bãi cát, đất công nghiệp,... Đặc biệt ở đây có rừng quốc gia Xuân Thuỷ là khu Ramsar đầu tiên tại Việt Nam và được đánh giá là Khu dự trữ sinh quyển thế giới đất ngập nước châu thổ Sông Hồng do Tổ chức Giáo dục, Khoa học và Văn hoá của Liên Hiệp Quốc (UNESCO) chính thức công nhận ngày 02/12/2004. Cồn Vành, Cồn $\mathrm{Lu}, \ldots$ cũng nằm trong hệ thống rừng ngập mặn ven biển có nhiều tiềm năng thuận lợi để phát triển du lịch sinh thái và nghỉ dưỡng lý tưởng và hấp dẫn. Do vậy, việc nghiên cứu lớp phủ thực vật (đặc biệt là lớp phủ rừng) có ý nghĩa quan trọng trong công tác quy hoạch tổng thể và quản lý tài nguyên đất đai của vùng cửa sông Ba Lạt.

\section{Tư liệu và phương pháp nghiên cứu}

\subsection{Tu liệu nghiên cứu}

- Ảnh vệ tinh Landsat 5TM chụp ngày 1 tháng 11 năm 2011 khu vực nghiên cứu.

- Bản đồ Hiện trạng sử dụng đất tỷ lệ 1:25000 huyện Giao Thủy tỉnh Nam Định và Tiền Hải tỉnh Thái Bình năm 2010.

- Ảnh vệ tinh Google Earth chụp ngày 20 tháng 12 năm 2011. 
- Phần mềm Erdas, eCognition, Arcgis.

\subsection{Phwơng pháp phân loại hướng đối tự̆ng}

Phân loại hướng đối tượng được đề xuất và được ứng dụng trong các nghiên cứu từ những năm 1970 với những ưu thế rõ rệt hơn so với phương pháp phân loại dựa trên điểm ảnh [4]. Những ưu thế của phương pháp này thể hiện ở việc khi xác định các đối tượng trên ảnh, phương pháp này không chỉ dựa trên thông tin giá trị và đặc tính quang phổ như phương pháp phân loại dựa trên điểm ảnh, mà còn dựa trên nhiều thông số của đối tượng như: hình dạng, kích thước, độ chặt, độ mịn và thông tin ngữ cảnh với các đối tượng hình ảnh liền kề [6].

\subsubsection{Phân mảnh ảnh}

Phân mảnh ảnh là sự chia nhỏ hình ảnh thành các phần nhỏ (segment) dựa trên các tiêu chí: màu sắc (color), hình dạng (shape), độ chặt (compactness), độ trơn (smoothness). Ngoài ra, việc lựa chọn tham số tỷ lệ (scale parameter) là rất quan trọng và có tác động trực tiếp đến kích thước các đối tượng trên ảnh. Do đó, tùy thuộc vào từng loại ảnh vệ tinh, độ lớn và sự tách biệt của các đối tượng trong khu vực nghiên cứu, tham số này được lựa chọn là khác nhau. Chất lượng của việc phân mảnh ảnh trực tiếp tác động đến kết quả phân loại vệ tinh [4,6].

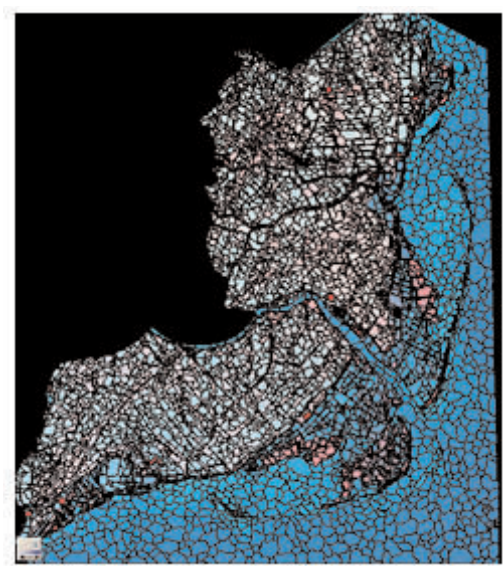

Hình 1: Anh năm 2011 vùng cưa sông Ba Lạt được phân mảnh theo cấp độ 1
Các tham số cho phân mảnh ảnh năm 2011 được kiểm tra và chạy thử nhiều lần. Kết quả là đã phân mảnh ảnh này theo 2 cấp độ: cấp độ 1 với các tham số tỷ lệ (scale) - hình dạng (shape) - độ chặt (compactness) và cấp độ 2 với tham số spectral difference 3. (Xem hình 1, 2)

\subsubsection{Xây dụng bảng chú giải[8]}

Các yếu tố sử dụng để thiết lập thông tin sử dụng đất liên quan đến chức năng sử dụng đất và các hoạt động được xác định, mô tả trên bề mặt khu vực nghiên cứu. Loại hình sử dụng đất của vùng cửa sông $\mathrm{Ba}$ Lạt được xác định theo chức năng kinh tế, việc phân biệt mức độ chi tiết hơn của các loại lớp phủ đất dựa vài tiêu chí kinh tế khác nhau để gán vào các lớp sử dụng đất theo chức năng chính của khu vực. Vùng của sông $\mathrm{Ba}$ Lạt được gán cho những lớp phủ theo bảng sau: (Xem bảng 1)

\subsubsection{Lấy mẫu và phân loại đối tượng \\ a. Chọn mẫu}

Việc chọn mẫu được thực hiện cho các nhóm đối tượng trên phần mềm eCognition bao gồm: đất xây dựng, đất trồng lúa, rừng ngập mặn, vườn tạp, đất NTTS, đất mặt nước, đất làm muối, đất chưa sử dụng. (Xem hình 3, bảng 2)

Dựa trên mẫu đã chọn, tiến hành phân loại, kết quả thu được như hình vẽ sau: (Xem hình 4)

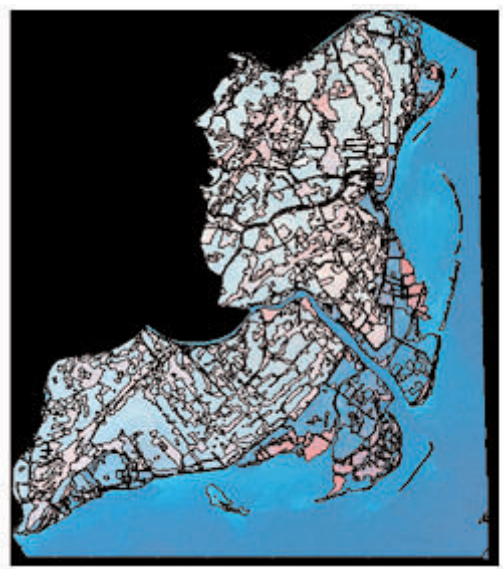

Hình 2: Anh năm 2011 vùng cưa sông Ba Lạt được phân mảnh theo cấp độ 2 
Bảng 1: Bảng hệ thống lớp phủ đất vùng của sông Ba Lạt

\begin{tabular}{|l|l|l|}
\hline \multicolumn{1}{|c|}{ Lớp phủ bề mặt } & \multicolumn{1}{|c|}{$\begin{array}{c}\text { Các lớp sử dụng } \\
\text { đất chi tiết }\end{array}$} & \multicolumn{1}{|c|}{ Mô tả chi tiết từng loại đất } \\
\hline $\begin{array}{l}\text { Các đối tượng nhân } \\
\text { tạo }\end{array}$ & Đất xây dựng & $\begin{array}{l}\text { Là loại đất được bao phủ bên trên bằng } \\
\text { các chất liệu bê tông, ví dụ như nhà ờ } \\
\text { công trình giao thông, khu công nghiệp ... }\end{array}$ \\
\hline Thực vật & Đất trồng lúa & Khu vực chuyên canh lúa \\
\hline & Đất rừng ngập mặn & Khu vực có các loại cây ngập mặn \\
\hline Vườn tạp & $\begin{array}{l}\text { Đất lẫn trong khu dân cư đề trồng trọt cây } \\
\text { ăn quả hoặc cây hoa màu }\end{array}$ \\
\hline & Đất NTTS & Khu vực chuyên để nuôi trồng thủy sản \\
\hline Đất khác & Đất mặt nước & Mặt nước biển, ao hồ, sông suối \\
\hline & Đất làm muối & Đất chuyên làm muối \\
\hline & Đất chưa sử dụng & Cồn cát, bãi cát \\
\hline
\end{tabular}

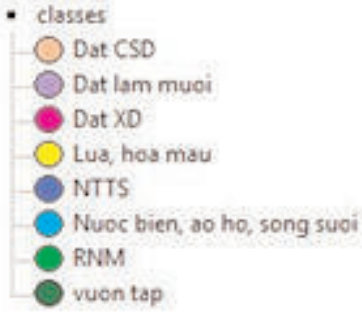

Hình 3: Các mâu được chọn

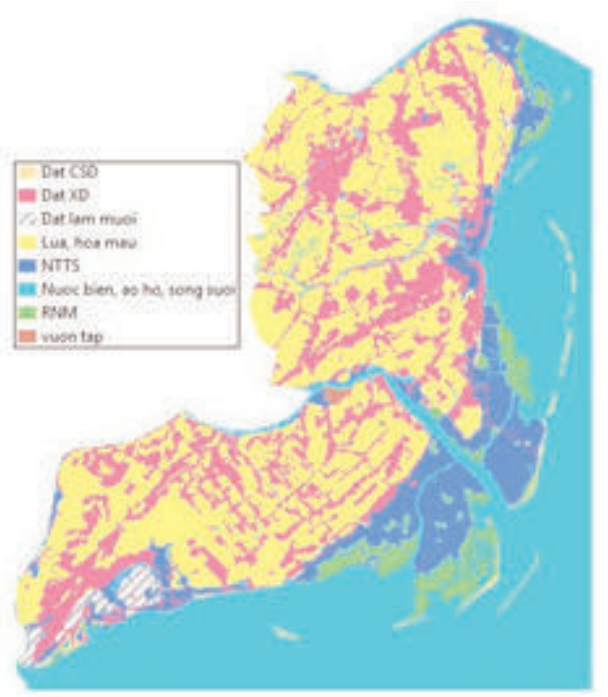

Hình 4: Hiện trạng lớp phủ vùng cưa sông Ba Lạt

2.3. Đánh giá độ chính xác kết quả phân loại lớp phủ vùng cửa sông Ba Lạt năm 2011

Việc đánh giá độ chính xác kết quả phân loại dựa trên bản đồ hiện trạng sử dụng đất năm 2010 khu vực nghiên cứu và ảnh vệ tinh Google Earth độ phân giải cao gần nhất với thời điểm nghiên cứu. Trong đó, bản đồ được sử dụng để giải đoán đối tượng, ảnh vệ tinh gần với thời điểm nghiên cứu được sử dụng để lấy ranh giới đối tượng (bảng 2). Đối với kết quả phân loại theo kỹ thuật định hướng đối tượng, kết quả các lớp chuyên đề hiển thị là các đối tượng đã được tạo vùng nhờ quá trình phân mảnh ảnh (Segmentation). Do đó, quá trình đánh giá độ chính xác dựa trên các dữ liệu tham khảo cũng bắt buộc phải dựa trên đa giác hoặc vùng đối tượng $[5,7]$.

$$
N=\frac{Z^{2} \times(p) \times(q)}{E^{2}}
$$

Trong đó:

- p là phần trăm độ chính xác kỳ vọng của toàn bản đồ

$-\mathrm{q}=100-\mathrm{p}(\%)$

- E là sai số cho phép

$-\mathrm{Z}=2$ từ độ lệch chuẩn thông thường của 1.96 cho $95 \%$ độ tin cậy

- $\mathrm{N}$ là số lượng ô mẫu

Với độ chính xác kỳ vọng cho kết quả phân loại sử dụng đất được tạo ra từ ảnh landsat $\mathrm{TM}$ năm 2011 là $85 \%$, sai số cho phép đạt $10 \%$, số lượng vùng mẫu được tính ra từ công thức trên là 51 , đây là số lượng ô mẫu tối thiểu mà chuyên 
đề bắt buộc phải lựa chọn trên toàn ảnh để đưa vào đánh giá độ chính xác có được độ chính xác kỳ vọng là $85 \%$. Do đó, chúng tôi đã lựa chọn 65 ô mẫu nhằm đánh giá độ chính xác tốt hơn, tuy nhiên số lượng ô mẫu không chia đều theo 8 lớp sử dụng đất, mà chia theo tiêu chí dựa trên độ phức tạp của mỗi lớp chuyên đề. Số ô mẫu này được lấy theo quy tắc lẫy mẫu ngẫu nhiên, ưu điểm chính của phương pháp lấy mẫu ngẫu nhiên là tính thống kê tốt đạt được từ kết quả của sự ngẫu nhiên lựa chọn mẫu. (Xem bảng 3)
Sau khi thành lập bảng ma trận sai số từ kết quả phân loại ảnh năm 2011 và bản đồ hiện trạng sử dụng đất năm 2010 và ảnh vệ tinh Google Earth tháng 12 năm 2011thì sẽ cho thấy sai số của từng lớp đối tượng chuyên đề, để từ đó tính độ chính xác tổng thể và hệ số Kappa từ bảng 4 :

- Độ chính xác tổng thể: $\mathrm{r}=1566.1 / 1735.6=$ $90.24 \%$

- Producer's Accuracy min-max:

- Mặt nước $=82 \%$

Bảng 2: Bảng sánh mẫu đối tương trên ảnh, trên bản đồ và trên Google Earth

\begin{tabular}{|c|c|c|c|}
\hline Lớp phü & Mẫu & $\begin{array}{l}\text { Vùng mẩu trên bãn đồ } \\
\text { hiện trạng } 2010\end{array}$ & 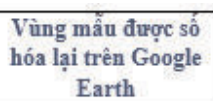 \\
\hline \multicolumn{4}{|l|}{$\begin{array}{l}\text { Dất xây } \\
\text { dụmg }\end{array}$} \\
\hline \multicolumn{4}{|l|}{$\begin{array}{l}\text { Đát trờng } \\
\text { lúa }\end{array}$} \\
\hline \multicolumn{4}{|l|}{$\begin{array}{l}\text { Đátr timg } \\
\text { ngạp mạ̣n }\end{array}$} \\
\hline \multicolumn{4}{|l|}{ Vươn tapp } \\
\hline \multicolumn{4}{|l|}{ Đát NTTS } \\
\hline \multicolumn{4}{|l|}{$\begin{array}{l}\text { Dát măt } \\
\text { nurợn }\end{array}$} \\
\hline \multicolumn{4}{|l|}{$\begin{array}{l}\text { Đá́t làm } \\
\text { muồi }\end{array}$} \\
\hline Đất chura & & & \\
\hline sừ dụng & & & \\
\hline
\end{tabular}


Bảng 3: Số lượng mẫu và diện tích vùng mẫu

\begin{tabular}{|l|c|c|c|}
\hline \multicolumn{1}{|c|}{ Lớp thông tin } & Số lượng mẫu & $\begin{array}{c}\text { Diện tích vùng } \\
\text { mẫu (ha) }\end{array}$ & $\begin{array}{c}\text { Diện tích sau phân } \\
\text { loại tương ứng với } \\
\text { vùng mẫu (ha) }\end{array}$ \\
\hline Đất CSD & 4 & 24.3 & 24.7 \\
\hline Đất làm muối & 4 & 158.3 & 149.1 \\
\hline Đất XD & 20 & 409.4 & 404.9 \\
\hline Lúa, hoa màu & 14 & 252.0 & 269.6 \\
\hline NTTS & 9 & 479.8 & 468.0 \\
\hline Mặt nước & 5 & 106.1 & 125.2 \\
\hline RNM & 7 & 302.0 & 289.2 \\
\hline Vườn tạp & 2 & 3.7 & 4.9 \\
\hline Tổng & $\mathbf{6 5}$ & $\mathbf{1 7 3 5 . 6}$ & $\mathbf{1 7 3 5 . 6}$ \\
\hline
\end{tabular}

Bảng 4: Ma trận kết quả phân loại năm 2011

\begin{tabular}{|l|c|c|c|c|c|c|c|c|c|c|}
\hline Loại đất & $\begin{array}{c}\text { Đất } \\
\text { CSD }\end{array}$ & $\begin{array}{c}\text { Đất } \\
\text { làm } \\
\text { muối }\end{array}$ & $\begin{array}{c}\text { Đất } \\
\text { XD }\end{array}$ & $\begin{array}{c}\text { Lúa, } \\
\text { hoa } \\
\text { màu }\end{array}$ & NTTS & $\begin{array}{c}\text { Mặt } \\
\text { nước }\end{array}$ & RNM & $\begin{array}{c}\text { Vườn } \\
\text { tạp }\end{array}$ & $\begin{array}{c}\text { Tổng } \\
\text { cột }\end{array}$ & $\begin{array}{c}\text { User's } \\
\text { Accuracy }\end{array}$ \\
\hline Đất CSD & $\mathbf{2 2 . 1}$ & 1.6 & 0.0 & 0.0 & 0.9 & 0.0 & 0.0 & 0.0 & 24.7 & 0.90 \\
\hline Đất làm muối & 0.0 & $\mathbf{1 4 8 . 8}$ & 0.2 & 0.0 & 0.0 & 0.0 & 0.0 & 0.0 & 149.1 & 1.00 \\
\hline Đất XD & 0.0 & 2.4 & $\mathbf{3 6 1 . 9}$ & 20.5 & 17.4 & 2.6 & 0.0 & 0.0 & 404.9 & 0.89 \\
\hline Lúa, hoa màu & 0.0 & 0.1 & 43.7 & $\mathbf{2 2 2 . 8}$ & 1.2 & 1.8 & 0.0 & 0.0 & 269.6 & 0.83 \\
\hline NTTS & 0.0 & 5.4 & 2.5 & 0.6 & $\mathbf{4 4 1 . 0}$ & 13.3 & 5.0 & 0.2 & 468.0 & 0.94 \\
\hline Mă̆t nước & 2.1 & 0.0 & 0.9 & 8.0 & 10.3 & $\mathbf{8 6 . 5}$ & 17.4 & 0.0 & 125.2 & 0.69 \\
\hline RNM & 0.0 & 0.0 & 0.2 & 0.0 & 9.0 & 0.4 & $\mathbf{2 7 9 . 6}$ & 0.0 & 289.2 & 0.97 \\
\hline Vườn tapp & 0.0 & 0.0 & 0.0 & 0.0 & 0.0 & 1.5 & 0.0 & 3.4 & 5.0 & 0.69 \\
\hline Tổng hàng & 24.3 & 158.3 & 409.4 & 251.9 & 479.8 & 106.2 & 302.0 & 3.7 & $\mathbf{1 7 3 5 . 6}$ & \\
\hline $\begin{array}{l}\text { Producer's } \\
\text { Accuracy }\end{array}$ & 0.91 & 0.94 & 0.88 & 0.88 & 0.92 & 0.82 & 0.93 & 0.93 & & \\
\hline
\end{tabular}

Bảng 5: Thống kê diện tích lớp phủ vùng cưa sông Ba Lạt

\begin{tabular}{|c|l|c|c|}
\hline STT & \multicolumn{1}{|c|}{ Lớp phủ } & Diện tích (ha) & $\begin{array}{c}\text { Diện tích trên bản } \\
\text { đồ hiện trạng } \\
\text { năm2010 (ha) }\end{array}$ \\
\hline 1 & Lúa & 20253.3 & 20565.0 \\
\hline 2 & RNM & 2141.8 & 4924.6 \\
\hline 3 & Vườn tạp & 243.2 & 559.4 \\
\hline 4 & Mặt nước & 26017.5 & 36111.4 \\
\hline 5 & Đất NTTS & 6439.6 & 3956.6 \\
\hline 6 & Đất xây dựng & 11870.3 & 8702.1 \\
\hline 7 & Đất làm muối & 603.6 & 645.4 \\
\hline 8 & Đất CSD & 635.1 & 1429.4 \\
\hline & Tổng & $\mathbf{6 8 2 0 4 . 4}$ & 7689.9 \\
\hline
\end{tabular}


- Đất làm muối =94\%

- User's Accuracy min-max:

- Vườn tạp $=69 \%$

- Đất làm muối $=100 \%$

- Hệ số Kapa $=\frac{1735.6 \times 1566.1-583092}{1735.6^{2}-583092}=0.88$

Độ chính xác tổng thể và hệ số Kapa của ảnh phân loại đạt được tương đối cao. Chứng tỏ độ tin cậy của kết quả phân loại đủ cơ sở để trở thành dữ liệu gốc cho việc giải đoán các ảnh tiếp theo bằng phương pháp phân vùng đối tượng.

Sau khi có kết quả phân loại, thống kê diện tích lớp phủ ta được số liệu theo bảng sau: (Xem bảng 5)

\section{Kết luận}

Việc sử dụng kỹ thuật phân loại hướng đối tượng (Object-oriented classification), với độ chính xác tổng thể $90.24 \%$ và hệ số Kapa 0.88 , cho kết quả phân loại đạt độ chính xác cao. Vì vậy, có thể sử dụng kỹ thuật phân loại hướng đối tượng để phân loại lớp phủ đất cho khu vực nghiên cứu và các khu vực tương tự. $\bigcirc$

\section{Tài liệu tham khảo}

[1]. Nguyễn Văn Thị, Trần Quang Bảo (2014), Úng dụng kỹ thuật phân loại ảnh đối tương nhăm phân loại trạng thái rùng theo tông tư số 34, Tạp chí KHLN 2/2014 (3343-3353).

[2]. Trịnh Thị Hoài Thu (2015), Nghiên cúu tác động của quá trình đô thị hóa đến cơ cấu sủ dụng đất nông nghiẹp khu vục Đông Anh - Hà Nội, Luận án tiến sĩ

[3]. Lê Thị Thu Hà (2016), Nghiên cứu biến động sư dụng đất trong mối quan hệ với một số yếu tố nhân khẩu học thuộc khu vưc huyện Giao Thủy, tỉnh Nam Định, Luận án tiến sĩ.

[4]. Definiens (2009), "eCognition Developer 8 Reference Book", User Guide, Definiens AG, $1.2 .0,34-38$

[5]. Foody (2002b), "Status of land cover classification accuracy assessment", Remote Sensing of Environment, 80, 185-201.

[6]. Liu Yongxue, Li Manchun, Mao Liang, $\mathrm{Xu}$ Feifei, Huang Shuo (2006), "Review of Remotely Sensed Imagery Classification Patterns Based on Object-oriented Image Analysis", Chinese Geographical Science 16 (3), 282-288.

[7]. Russell G. Congalton, Kass Green (2008), Assessing the Accuracy of Remotely Sensed Data: Principles and Practices, Taylor \& Francis Group.

[8]. Kauth, Thomas (1976), "The tasselled capa graphic description of the spectral temporal development of agricultural crops as seen by Landsat", Proceedings of the 2nd Annual Symposium on Machine Processing of Remotely sensed data held at Purdue University in 1976, 41-49.

\section{Summary}

\section{APPLYING OBJECT - BASE IMAGERY CLASSIFICATION TECHNIQUE TO CLAS- SIFY LAND COVER ON THE}

\section{Tran Thi Ngoan}

This article presents a result of applying object - base imagery classification technique to Land Cover status based of $\mathrm{Ba}$ Lat river area by Landsat 5TM Image. This process is done in 3 steps: segmentation, sampling and object classification, checking and assessing the accuracy of classification results. Segmented imagery were classified in to 8 statuses of land cover paddy land, mangroves, mixed garden, water surface, aquaculture land, construction land, salt making land and unused land. The classification results for high accuracy with an overall accuracy of $92.24 \%$ and Kapa coefficient of 0.88 . 